\title{
ESTADO DA ARTE DOS SÍTIOS ARQUEOLÓGICOS COM SEPULTAMENTOS NO ESTADO DE ALAGOAS
}

\author{
Andréia Caroline Gonçalves Silva ${ }^{i}$ \\ Tatiane Maria Soaresii \\ Flávio Augusto de Aguiar Moraes iii
}

Resumo: O estado de Alagoas, localizado na região Nordeste do Brasil, dispõe de um rico acervo arqueológico, especialmente os sítios de registro rupestre na porção sertaneja. No que se refere aos sítios de contextos funerários nesse estado, percebe-se que há uma escassez, sendo identificados até o momento três sítios: Baixa das Flores em Limoeiro de Anadia; Alazão, em Arapiraca; e o sítio São José II, na cidade de Delmiro Gouveia. Exatamente em virtude dessa baixa recorrência de sítios funerários, os que foram estudados apresentam uma elevada importância no que se refere ao conhecimento das práticas funerárias compartilhadas pelos grupos que habitaram em tempos pretéritos este território. Assim, este trabalho tem por objetivo apresentar o estado da arte de sítios arqueológicos de contexto funerário identificados no estado de Alagoas, buscando perceber quais as metodologias utilizadas durante as atividades de campo e análises de laboratório, no âmbito dos aspectos bioculturais, pontuando os resultados obtidos, e se esses são distintos a depender da metodologia utilizada. Palavras-Chaves: Arqueologia da Morte, Sepultamentos, Alagoas.

iandreia.caroline.g@gmail.com Universidade Federal de Alagoas UFAL;

iitat.msoarez@gmail.com Universidade Federal de Sergipe UFS;

1flavioaguiarac@gmail.com Universidade Federal de Alagoas UFAL.

\begin{abstract}
The state of Alagoas, located in northeast region of the Brazil have a rich archaeological collection, especially the rupestrian record sites in sertaneja region. Regarding the funeral sitios they are scarce, because only three sitios was discovered: Baixa das Flores at Limoeiro de Anadia; Alazão at Arapiraca and Sítio São Jose II in Delmiro Gouveia city. Because of these few funeral sitios discovered, the already found are very important around your death practices, shared to peoples that lived at the past time. Thus, this work has as objective show the art state about funerary archaeological sites found in Alagoas state, trying meet which the methodologies used at field activities and laboratory analysis, around the biocultural aspects, after highlight the results, e if these are different when different methodologies are used. Keywords: Archeology of Death, Burials, Alagoas.
\end{abstract}




\section{Introdução}

A região Nordeste do Brasil é composta por um rico acervo de Sítios Arqueológicos de contexto funerário que tem/vem contribuí[n]do, significativamente, para os conhecimentos acerca das práticas mortuárias nos contextos funerários. Dentre esses podemos citar, conforme é apresentado na pesquisa de Soares (2019): o Sítio Justino - Sergipe (Santos, 2007; Santana, 2013; Santana e Carvalho, 2013; Silva e Carvalho, 2013); Sítio Furna do EstragoPernambuco, (Menezes e Queiroz, 2006; Silva, 2015; Leite et al, 2014, Castro, 2018; Souza, 2008), Sítio Gruta do Padre- Pernambuco, (Oliveira, 1942; Etchevarne, 1999-2000; Martin, 1994). Sítio Cemitério do Caboclo- Pernambuco, (Amaral, 2007; Perazzo et al, 2017), Sítio Pedra do Caboclo- Pernambuco, (Leite et al, 2014), Sítio Alcobaça- Pernambuco, (Nascimento et al, 1996; Cisneiros, 2004; Leite et al, 2014), Sítio Pedra do Alexandre- Rio Grande do Norte, (Martin, 1995; Ramos, 1996) e Sítio Furna dos Ossos- Rio Grande do Norte, (Lima et al, 2017). Também podemos citar o sítio Lajedo do Cruzeiro - Paraíba (Soares, 2019).

Assim, situado no estado de Sergipe, no município de Canindé de São Francisco, temos o Sítio arqueológico Justino, (Santos, 2007; Santana, 2013; Santana e Carvalho, 2013; Silva e Carvalho, 2013), cujo nos últimos anos tem possibilitado descobertas importantes sobre as populações que viveram nessa região, do Baixo São Francisco, no período da pré-história. O sítio Justino está localizado nas imediações da fazenda cabeça do negro, as margens do rio São Francisco. Na década de 1980, alguns arqueólogos da Universidade Federal de Sergipe, constataram que a região era bastante propicia para detectar os primeiros sítios arqueólogos. Diante disso, nessa mesma época a companhia Hidrelétrica do rio são Francisco (Chesf), responsável pela construção da Hidrelétrica, juntamente com Universidade Federal de Sergipe, firmaram parceria para investiga e resgata o Patrimônio arqueológico que possivelmente podia encontrar na região. O sítio foi descoberto em 1990, identificado em um terraço fluvial, em uma área de $1.532,50 \mathrm{~m}^{2}$, com datações cronológicas de 12.220 a 1.800 anos $A$. $P$, a céu aberto, o material resgatado foi aproximadamente mais de 200 esqueletos humanos.

Sobre o sítio Silva (2017), descreve que nas pesquisas sobre o Sítio, permitiram informações valiosas vinculadas a ocupação do baixo São Francisco, diante da quantidade e complexidade dos materiais resgatados. No Sítio foi resgatado uma quantidade considerável de vestígios cerâmicos com enterramentos, sendo considerado um dos maiores cemitérios indígenas escavados no Brasil. 
No trabalho de Vergne (2004), apresenta sobre o sítio ainda as seguintes informações:

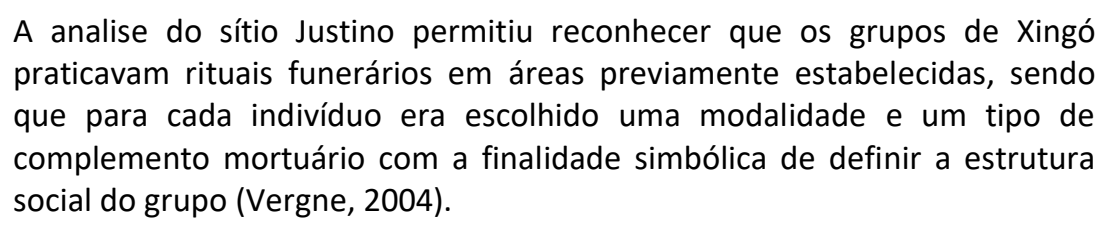
Vergne (2004), ainda aponta para a categorização de hierarquias sociais, distinção de gêneros e idades nos tipos de enterramentos dos cemitérios $A, B, C$. Principalmente no $B$, no cemitério D não é possível observar distinções visíveis, pelo menos de acordo com a análise dos vestígios materiais aos enterramentos.

No estado de Pernambuco identificou-se alguns sítios arqueológicos de contexto funerário, que tem permitido informações relevantes sobre os grupos que habitaram este estado, sendo eles: Sítio Furna do Estrago- Pernambuco, (Menezes e Queiroz, 2006; Silva, 2015; Leite et al, 2014, Castro, 2018, Souza, 2018), Sítio Gruta do Padre- Pernambuco, (Oliveira, 1942, Etchevarne, 1999-2000 e Martin, 1994). Sítio Cemitério do caboclo- Pernambuco, (Amaral, 2007; Perazzo et al, 2017; Leite et al, 2014), Sítio Pedra do Caboclo- Pernambuco, (Leite et al, 2014), Sítio Alcobaça- Pernambuco, (Nascimento et al, 1996; Cisneiros, 2004; Leite et al, 2014).

O sítio arqueológico Furna do Estrago está situado no município do Brejo da Mãe de Deus, trata-se de sítio pré-histórico, em abrigo sob rocha, as datações é aproximadamente entre 11060 a 1040 anos B.P. As pesquisas de campo nesse sítio procederam em duas fases, a primeira foi inicialmente em 1983 e a segunda em 1987, sobre a responsabilidade da arqueóloga Jeannette Maria Dias de Lima, juntamente com a equipe do Laboratório de Arqueologia da (UNIPAN), o material resgato apontaram que o local tanto foi utilizado pelos habitantes como sítio habitação, como sítio cemitério em períodos distintos.

Como é apresentado por Lima (1985), O sítio Furna do Estrago, embora seja um sítio de abrigo sob rocha, foi ocupado de maneira diferenciada pelos menos em dois períodos distintos, sendo um sítio de habitação a cerca de 9000 anos e sítio cemitério a cerca de 2000 anos, B.P. Em torno de 8500 anos B.P., o sítio foi abandonado pelo o grupo de caçadores coletores que viviam no local, diante das mudanças climáticas.

Souza (2018) salienta que o sítio Furna do Estrago em virtude do material resgatado, possibilitou que fossem abertas diversas linhas de pesquisas, tanto no aspecto referente as 
pesquisas de campo, como nas pesquisas laboratoriais e principalmente por ser um dos sítios de maior informação de sítios de contextos funerários do Brasil.

Segundo Lima (1985), durante o período que o sítio foi utilizado apenas como cemitério, os habitantes provavelmente teriam aldeamentos nas imediações. E apesar das perturbações frequentes para a reutilização do local do sítio para os enterramentos, em grande parte estava em boas condições, o que facilitou as analises dos sepultamentos e esqueletos.

Souza (2018), ainda descreve acerca do sítio as seguintes informações:

Dotado de grande potencial que ainda aguarda ser desenvolvido nos próximos anos, a Furna do Estrago, e principalmente seu conjunto de sepultamentos humanos, permitem ainda muitos estudos. Ainda que este cemitério corresponda a apenas um curto período de uso intensivo daquele local, foi sem dúvida um dos mais interessantes achados arqueológicos em décadas (Souza, 2018: 46).

O sítio Gruta do Padre, em Itaparica- Pernambuco, trata-se de um sítio em um abrigo rochoso, a cronologia é aproximadamente 2000 anos B.P, durante a década 1960 iniciou-se as escavações deste sítio organizado Calderón nas pesquisas. Segundo Etchevarne (1999-2000), no sítio foi identificado que passou por quatro momentos de ocupação. Ainda é atribuído por Martin (1994), que a gruta do sítio foi usada frequentemente como um Ossuário no sentido de ser colocado os restos das cremações humanas, mais do que um local de rituais fúnebres.

O Sítio Cemitério do caboclo no município de ventura, no sopé da serra do Bocu, em Pernambuco, está localizado em um abrigo rochoso. As escavações do sítio se deram a partir da década de 1980 por V. Luft. Amaral (2007), descreve que o sítio tinha como caraterística principal, a presença de enterramentos secundários, durante as pesquisas observou-se a desordem e desarticulação dos ossos, assim como perceberam a prática de cremação. Leite et al (2014) atribui sobre o sítio, que os ossos estavam bastante queimados e fragmentados, sendo raro no material a presença de ossos inteiros, o que se dá ao fato da presença de fogueiras sobre eles, não permitindo a definição de sexo ou idade.

O sítio Pedra do Caboclo, situado no município de Bom Jardim- Pernambuco, trata-se de um sítio de abrigo sob rocha, as escavações no sítio foram durante os anos de 1968 e 1974, coordenado por A. Laroche. Segundo Leite et al (2014), em um local específico denominada sala de enterramento, foram identificados materiais ósseos calcinados e carbonizados, no local também foram encontrados vários fragmentos cerâmicos o que pode indicar que urnas foram utilizadas nos enterramentos. 
Ainda no estado de Pernambuco, tem o sítio de contexto funerário Alcobaça localizado no município de Buíque, este sítio teve seu período de escavações de 1996 a 2001, coordenado pela a arqueóloga Ana Nascimento, as datações obtidas são entre $1812 \pm 26$ anos B.P e $2405 \pm 30$ anos B.P. Cisneiros (2004), aponta que no sitio os cinco enterramentos identificados tratavamse de sepultamentos secundários e estavam depositados em covas sem aparente ordenamento, os ossos apresentavam bastante fragmentados, tornando difícil a identificação do sexo e idade dos esqueletos. Cisneiros (2004), ainda salienta que em todos os enterramentos foi possível identificar a presença de fogueiras, os ossos dos esqueletos apresentavam alterações compatíveis em diversos graus ao processo pós-morte, e em nenhum caso foi identificado carbonização.

No estado do Rio Grande do Norte, identificou os sítios arqueológicos de contexto funerário: Sítio Pedra do Alexandre- Rio Grande do Norte, (Martin, 1995; Ramos, 1996; Torres, 19851996) e Sítio Furna dos Ossos- Rio Grande do Norte, (Lima et al, 2017).

Na microrregião do Seridó, identificou-se o sítio Pedra do Alexandre, situado no município de Carnaúba dos Dantas, trata-se de um sítio de abrigo sob rocha, com uma cronologia de 9400 a 2620 anos B.P. Sobre o sítio Torres (1985-1996), apresenta que é formado por abrigo rochoso e além das pinturas rupestres presentes em seu paredão, foram encontrados enterramentos humanos com os esqueletos pintados de vermelho e fragmentos de óxido de ferro com marcas de uso.

No estado do Rio Grande do Norte, ainda foi identificado o sítio Furna dos Ossos, situado no município de Santana dos Matos, o sítio em questão está localizado em uma região semi-árida, de clima seco e vegetação predominante da caatinga, segundo informações de (Lima et al, 2017). Ainda conforme Lima et al (2017), a coleta do material ósseo em superfície no sítio foi realizada de maneira sistemática, visando exclusivamente o salvamento do material, pois encontravam-se em superfície, sem relação com a disposição vertical e horizontal de quando foram realizados os sepultamentos.

No estado da Paraíba, foi identificado através do Institudo Memorial da Borborema e do Nucleo de Pesquisas e Estudos Arqueológicos (Nupeah-UFAL) o sítio Lajedo do Cruzeiro que está localizado no município de Pocinhos. Esse sítio caracteriza-se como um abrigo sob rocha e apresentou material ósseo, lítico e acompanhamentos funerários como as contas de colar e pingentes que foram analisadas por Soares (2019). 
Tratando-se do estado de Alagoas, localizado na região nordeste do Brasil, é possível identificar, até então, três Sítios Arqueológicos de contexto funerário, são eles: o Sítio São José II, o Sítio Baixa das Flores e o Sítio Alazão, os quais serão descritos ao decorrer deste trabalho.

O Sítio São José II, localizado no município de Delmiro Gouveia, nas proximidades da fazenda São José, as margens do rio São Francisco, onde foi identificado durante o projeto de salvamento para a construção da hidrelétrica de Xingó, teve o período de escavações de 1993 a 1994, pela a equipe do Museu Arqueológico de Xingó (Max). Segundo (Carvalho e Vergne, 2001) e (Lima e Moraes, 2017), as datações cronológicas do sítio obtidas são de 3500 1110 B.P e $4140 \pm 90$ B.P.

O Sítio Baixa das Flores, localizado no município do Limoeiro de Anadia nas proximidades do curso do rio Coruripe, conforme (Moraes et al., 2014 e Lima e Moraes, 2017), foi escavado em 2012, as pesquisas foram desenvolvidas pelo o Núcleo de Ensino e Pesquisa Arqueológica (Nepa), juntamente com o Núcleo de Pesquisa de Estudos Arqueológicos e Históricos (NUPEAH), da Universidade Federal de Alagoas/ Campus Sertão, coordenado pelo o Arqueólogo Flávio Moraes de Aguiar, financiada pelo o instituto do Patrimônio Histórico e Artístico Nacional (Iphan). No Sítio através dos estudos foi identificado por um sítio indígena relacionada a cultura Aratu, com datação cronológica de $1530 \pm 30$ anos B.P.

O Sítio Alazão, situado no município de Arapiraca, próximo do rio Perucaba, como é descrito por (Santos, 2016), foi inicialmente identificado em 2010, pelo prof. Scott Allen, que realizou o salvamento emergencial de uma urna, sob o Programa de Prospecção Arqueológica, posteriormente, foi dado continuidade pela a Arqueóloga Deisi S. E. de Farias no ano seguinte.

As pesquisas e estudos destes sítios de contextos funerários, nos últimos anos tem relevando dados importantes, tanto em aspectos culturais dos grupos que ocuparam os respectivos estados, assim como revelam resultados das complexidades das relações sociais desses grupos ao decorrer do tempo. A partir disso, nos debruçaremos sobre os três sítios arqueológicos de Sepultamentos do estado de Alagoas, objetivando apresenta o estado da arte.

\section{Materiais e Métodos}

Analisamos, nesta pesquisa, os métodos de escavação utilizadas; análises de laboratório e os aspectos bioculturais: a localização dos sítios (se estão no litoral, sertão, agreste ou zona da 
mata), os tipos de sítios (a céu aberto ou abrigo sob rocha), os sepultamentos (se eram em urnas ou diretamente no solo); as características dos sepultamentos (se eram primário, secundário, coletivo ou múltiplo); acompanhamentos (se havia contas, fibras vegetais, artefatos) e esqueletos (se haviam com pigmentos de ocre, com marcas de corte, idade da morte dos indivíduos, sexo).

A metodologia empregada será um levamento bibliográfico acerca de cada respectivo sítio, buscando compreender o que apresentam de distintos, dependendo da metodologia empregada. Utilizando informações descritas por (Lima e Moraes, 2017), (Carvalho e Vergne, 2001), (Moraes et al., 2014) e (Santos, 2016).

\section{Resultados Parciais}

Na análise bibliográfica realizada no Sítio São José II, foi identificado que a metodologia utilizada nas atividades de campo passou pelo os procedimentos de sondagem e prospecção. Nas análises laboratoriais foi realizado o trabalho de limpeza dos sedimentos nos materiais resgatados para melhor obtenção de resultados, foram analisados o estado de conservação, em seguida foi feito a catalogação dos materiais e um estudo tafonômico e paleopatológico. Quanto aos aspectos bioculturais (tabela 1), está inserido no sertão Alagoano, o sítio é a céu aberto, os sepultamentos foram diretamente no solo, foram detectados 22 Sepultamentos primários e 6 Sepultamentos secundários. Nos acompanhamentos foram encontrados conchas de moluscos, fogueiras e artefatos cerâmicos. O esqueleto 5 era um indivíduo do sexo feminino e o esqueleto 24 era um indivíduo do sexo masculino e possuía cortes ao nível da primeira vértebra lombar.

Na pesquisa acerca do sítio Baixa das Flores, foi identificado que a metodologia utilizada nas atividades de campo, foi a prospecção de superfície e subsuperfície e levantamento topográfico. As análises laboratoriais não são descritas. Tratando-se dos aspectos bioculturais (tabela 2), o sítio está localizado no Agreste Alagoano, é a céu aberto, os sepultamentos foram identificados em urnas, nos acompanhamentos foram encontrados vasilhames cerâmicos e 60 blocos de pedras no indivíduo 5, nos esqueletos foi possível identificar que o indivíduo 1 era do sexo feminino e tinha a idade aproximadamente entre 17 e 25 anos; o indivíduo 2 tinha idade entre 19 e 25, quanto ao sexo não foi realizada, devido a fragmentação óssea; o indivíduo 3 era do sexo masculino e tinha a idade entre 15 e 20 anos e o indivíduo 5 tinha a idade 
aproximadamente de 16 e 25 anos, não foi possível obter resultados do sexo, pois ocorreu a deterioração do material ósseo. No sítio havia 2 sepultamentos primários e 1 sepultamento secundário.

Tabela 1: Descrição dos resultados do Sítio São José II.

\begin{tabular}{|c|c|}
\hline \multicolumn{2}{|r|}{ Sitio São José II } \\
\hline Localização do Sítio: & - Sertão. \\
\hline Tipo do Sitio: & - A céu aberto. \\
\hline Sepultamentos: & - Diretamente no solo \\
\hline Características dos Sepultamentos: & $\begin{array}{l}\text { - } 22 \text { Sepultamentos primários; } \\
\text { - } 6 \text { Sepultamentos secundários. }\end{array}$ \\
\hline Acompanhamentos: & $\begin{array}{l}\text { - } \quad \text { Artefatos cerâmicos; } \\
\text { - } \quad \text { Fogueiras; } \\
\text { - Conchas de moluscos. }\end{array}$ \\
\hline Esqueletos: & $\begin{array}{l}\text { - } 29 \text { Sepultamentos; } \\
\text { - Sepultamento } 5 \text { era um indivíduo do sexo feminino; } \\
\text { - Sepultamento } 24 \text { era um indivíduo do sexo masculino e } \\
\text { possuía cortes ao nível da primeira vertebra lombar. }\end{array}$ \\
\hline
\end{tabular}

Tabela 2: Descrição do Sítio Baixa Flores.

\begin{tabular}{|c|c|}
\hline \multicolumn{2}{|r|}{ Sitio Baixa das Flores } \\
\hline Localização do Sítio: & - Agreste \\
\hline Tipo do Sitio: & - A céu aberto. \\
\hline Sepultamentos: & - Em urnas. \\
\hline Acompanhamentos: & $\begin{array}{l}\text { - Vasilhame cerâmico; } \\
\text { - } 60 \text { blocos de pedras no indivíduo } 5 .\end{array}$ \\
\hline Esqueletos: & $\begin{array}{l}\text { - Indivíduo } 1 \text { era do sexo feminino e tinha a idade aproximadamente } \\
\text { entre } 17 \text { e } 25 \text { anos; } \\
\text { - No indivíduo } 2 \text { tinha idade entre } 19 \text { e } 25 \text {, quanto ao sexo não foi } \\
\text { realizada, devido a fragmentação óssea; } \\
\text { - No indivíduo } 3 \text { era do sexo masculino e tinha a idade entre } 15 \text { e } 20 \\
\text { anos; } \\
\text { - No indivíduo } 5 \text { tinha a idade aproximadamente de } 16 \text { e } 25 \text { anos, } \\
\text { não foi possível obter resultados acerca do sexo, pois ocorreu a } \\
\text { deterioração do material ósseo. }\end{array}$ \\
\hline $\begin{array}{l}\text { Características dos } \\
\text { Sepultamentos: }\end{array}$ & $\begin{array}{l}\text { - } 2 \text { Sepultamentos primários, } \\
\text { - Urna } 5 \text { a única com sepultamento secundário. }\end{array}$ \\
\hline
\end{tabular}


No estudo sobre o sítio Alazão (tabela 3), foi identificado que a metodologia realizada nas atividades de campo foi levantamento cartográfico; geoprocessamento; registro gráfico do material arqueológico de superfície e em subsuperfície; a estratigrafia e registro fotográfico. Relacionado as análises laboratoriais, os materiais recolhidos passaram pelo os processos de limpeza, identificação dos fragmentos dos materiais e numeração de cada respectivo fragmento. Quanto os aspectos bioculturais: o sítio está situado no Agreste Alagoano; o sítio é a céu aberto; o indivíduo foi encontrado em uma urna funerária; com as características de um sepultamento primário. $\mathrm{O}$ acompanhamento funerário identificado nesse sítio foi uma urna, e apenas encontrado 1 esqueleto.

Tabela 3: Descrição do Sítio Alazão.

\begin{tabular}{|l|cl|}
\hline \multicolumn{2}{|c|}{ Sítio Alazão } \\
\hline Localização do Sítio: & $\bullet$ & Agreste. \\
\hline Tipo do Sitio: & $\bullet$ & A céu Aberto. \\
\hline Sepultamentos: & $\bullet$ & Na urna funerária. \\
\hline $\begin{array}{l}\text { Características dos } \\
\text { Sepultamentos: }\end{array}$ & $\bullet$ & Um único Sepultamento primário. \\
\hline Acompanhamentos: & $\bullet$ & Uma Urna funerária. \\
\hline Esqueletos: & $\bullet$ & Um esqueleto. \\
\hline Atividade de campo: & $\bullet$ & $\begin{array}{l}\text { Levantamento cartográfico; geoprocessamento; registro gráfico do } \\
\text { material arqueológico em superfície e em subsuperficie; estratigrafia } \\
\text { e acompanhamento fotográfico. }\end{array}$ \\
\hline Analise laboratorial: & $\bullet$ & $\begin{array}{l}\text { Higienização; identificação dos fragmentos dos materiais e } \\
\text { numeração dos materiais. }\end{array}$ \\
\hline
\end{tabular}

\section{Conclusões}

Os estudos acerca dos sítios Arqueológicos, tem demostrado que cada respectivo adotou metodologias de campo praticamente semelhantes, nos procedimentos de analises laboratorial tanto o Sítio São José II, quanto o Sítio Alazão seguiram procedimentos também semelhantes, embora o São José II, atentou-se para estudos mais precisos no material encontrado, como o estudo tafonômico e paleopatológico. No sítio Baixa das Flores não chega a ser descrito especificamente os procedimentos laboratoriais. 
Nos aspectos bioculturais o Sítio Alazão, precisamente nas caraterísticas de sepultamentos, é o único que apresenta apenas a caraterística de um tipo de sepultamento, assim como, reúne uma quantidade bem menor de materiais encontrados em comparação aos demais. O São José II, sobressair sobre os outros dois sítios em relação ao número de esqueletos e sepultamentos identificados nos trabalhos de campo e laboratorial, o sítio estudado ainda apresentou que um esqueleto do sexo masculino havia cortes, e é único que está situado no sertão da região do estado. O sítio Baixa das Flores desmonta que os vestígios recolhidos possibilitaram obter com mais precisão resultados vinculados a estimativa de idade e sexo, além disso, os resultados obtidos sobre os vasilhames cerâmicos resultaram que este sítio era da cultura ceramista aratu.

Desse modo, embora os estudos e descobertas de sítios arqueológicos no estado de Alagoas venham sendo realizadas recentemente, as pesquisas sobre os sítios Arqueológicos em questão apresentam uma significativa compreensão das práticas culturais dos contextos de morte compartilhada pelos grupos que habitaram o território, assim como, para a contribuição para o entendimento da ocupação dos grupos ceramistas nos tempos pretéritos dessa região.

\section{Referências}

AMARAL, M.P. V. 2007. Os Sítios de registros rupestres em Buíque, Venturosa e Pedra (PE) no contexto da geopaisagem. Dissertação (Mestrado) em Arqueologia- Universidade Federal de Pernambuco, Recife.

CARVALHO, O. A. de; VERGNE, C. 2001. Estudo paleodemográfico e tafonômico na população préhistórica da necrópole de São José II (Delmiro Gouveia, Alagoas, Brasil). Revista Canindé, v.1, n.1, p. 101-116.

CASTRO, V. M. C. de. 2018. Sítio Furna do Estrago, PE Práticas Funerárias e Marcadores de Identidades Coletivas. Clio arqueológica, v.33, n. 2, p. 330- 371.

CISNEIROS, D. 2004. Práticas funerárias na pré-História do Nordeste do Brasil. Dissertação (Mestrado), Programa de Pós-Graduação em História, Universidade federal de Pernambuco, Recife.

LEITE, M. N; CASTRO, V.C. de; CISNEIROS, D. 2014. Furna do estrago, Brejo da Madre de Deus- PE: Reflexões sobre o lugar dos mortos na paisagem. Fumdhamentos XI: p. 50-64.

LIMA, D V. R. de; MORAES, F. A. A. 2017. Estudo paleobiológico de restos humanos provenientes do Sítio Baixa das Flores, Limoeiro de Anadia, Alagoas, Brasil. Clio. Série Arqueológica (UFPE), v.32, p. 14-36.

LIMA, D. V. R. de; MORAES, F. A. A; SANTOS, J. S; JÚNIOR, V. S. 2017. O cemitério Furna dos ossos em Santana dos Matos-RN: Estudos preliminares dos restos osteológicos humanos encontrados em superfície. Clio, serie arqueológica (UFPE), v. 32, p. 17-47. 
LIMA, J. M. D de. 1985. Arqueologia da Furna do Estrago Brejo da Mãe de Deus- Pernambuco. Dissertação (Mestrado), apresentada ao programa de pós-graduação em antropologia da Universidade Federal de Pernambuco para obtenção do Grau de mestre em Antropologia, Recife.

MARTIN, G. 1994. Os Rituais Funerários na Pré-História do Nordeste. Clio- série Arqueológica, Recife, v. 1, n. 10, p. 29-46.

MARTIN, G. 1995. O Cemitério Pré-Histórico do sítio do Alexandre, Carnaúba dos Dantas, RN. ClioSérie Arqueológica, Recife, v. 1, n, 11, p. 43-57.

MENEZES, A. V. A.; QUEIROZ, A. N. de. 2006. Estudo dos macrorestos Vegetais do Sítio arqueológico Furna do Estrago, Brejo da Madre de Deus, Pernambuco, Brasil. Dissertação (Mestrado), Programa de Pós-Graduação em Antropologia, Universidade Federal de Pernambuco, Recife.

MORAES, F. A. A; MORAES, D. V. R. L; BARBOSA, R. F. (2014). A cultura Arqueológica aratu em Alagoas: O caso do Sítio Baixa das Flores, município de limoeiro de Anadia/ Capitulo IV. Org. ALMEIDA, Luiz Sávio de [et al.], Índios de Alagoas: História e Sociedade. Edufal/ Maceió, v. 16, p. 93-122.

NASCIMENTO, A; ALVES, C; LUNA, S. 1996. O Sítio Arqueológico Alcobaça, Buíque- Pernambuco: Primeiros Resultados. Clio, Série Arqueológica $v, 1, n, 11$.

OLIVEIRA, L.; KLOKLER, D. M. 1942. Os mortos e as oferendas: Compreendendo gênero no contexto funerário do sítio Justino. In: boletim do museu Nacional. P. 151-240. Rio de Janeiro.

PERAZZO, M.; RIOS, C.; PESSOA, R. J. R. 2017. Sítios com pinturas rupestres em Buíque, Venturosa e Pedra no contexto da geopaisagem, Pernambuco, Brasil. Boletim do museu paraense Emilio Goeldi. Ciências Humanas, v. 12, p. 125-133.

RAMOS, A. C. P. T. 1996. Estudo dos pigmentos do sítio Pré-Histórico Pedra do Alexandre- Carnaúba dos Dantas- RN. Clio. Série Arqueológica (UFPE), Recife, v. 11, n.1, p. 59-70.

SANTANA, A. D. D. 2013. Datação radiocarbonica- MAS do sítio Arqueológico Justino, região do Baixo são Francisco. Exame de qualificação Mestrado em Geociência e analise de bacias Universidade Federal de Sergipe, Sergipe.

SANTANA, E. A; CARVALHO, O. A. 2013. Fraturas nos ossos: violência, acidente ou bioturbação? Cadernos do LEPAARQ UFPEL, v. 10, p. 131- 157.

SANTOS, C. A. dos. 2016. Relatório Final de resgate do sítio Alazão, Arapiraca (AL): Programa de Resgate Arqueológico da LT 230 KV LT Rio largo/ Penedo - seccionamento Arapiraca Município de Arapicaraca (AL). Portaria no 12 de 11 de março de 2016, processo № 01403.000325/2011-83. Recife - Pernambuco.

SANTOS, J. O. 2007. Estudos Arqueométricos de sítios Arqueológicos do Baixo do São Francisco. 1. Ed. São Cristóvão, Sergipe: Museu de Arqueologia de Xingó. v.1.

SILVA, J. A; CARVALHO, O. A. 2013. Analise Arqueotanatológica de duas sepulturas infantis- Sítio Justino- SE. Clio, série Arqueológica (UFPE), v. 28, p. 74-104.

SILVA, R. A. P. 2015. Acompanhamentos funerários como marcadores culturais do sítio Préhistórico da Furna do Estrago- PE. Universidade Federal de Pernambuco, UFPE, Brasil, Recife. 
SOARES, T. M. 2019. Acompanhamentos funerários do Sítio Lajedo do Cruzeiro - Pocinhos / PB: identificação e caracterização das contas de colar e pingente. Trabalho de Conclusão de Curso (Licenciatura em História) - Unidade Delmiro Gouveia-Campus do Sertão, Universidade Federal de Alagoas, Delmiro Gouveia.

SOUZA, S. M. de. 2018. Arqueologia Funerária e a Furna do Estrago. Clio arqueológica, v. 33, n. 2, p. 44-92.

VERGNE, C. 2004. Arqueologia do Baixo São Francisco: estruturas funerárias do Sítio Justino região do Xingó, Canindé do São Francisco, Sergipe. Tese de doutorado, museu de arqueologia e etnologia- Universidade de São Paulo, São Paulo. 